\title{
A EXPANSÃO DO DIREITO PENAL E O DIREITO FUNDAMENTAL À LIBERDADE
}

Marcelo Carita Correra ${ }^{41}$

Recebido em: 21/10/2019

Aprovado em: 06/02/2020

\begin{abstract}
RESUMO
O presente trabalho busca estudar o conflito entre poder estatal e liberdade individual. A sociedade atual demanda a existência de um ente abstrato (Estado) com monopólio do uso da força, cuja função é regular o convívio na busca do bem comum. Essa construção conflita com a liberdade individual. Sempre que o Estado faz uso da força, como a criação de um tipo penal, há restrição da liberdade individual. Há necessidade de estabelecer um critério objetivo para fixar o limite do poder estatal frente à liberdade individual. A proposta testada e confirmada foi, para os países de direito continental, a utilização do conceito de bem jurídico protegido como forma de verificar a legitimidade da norma. Os países do commom law utilizariam o mesmo mecanismo, mas o conceito de bem jurídico protegido seria substituído pelo harm principle. Demonstrou-se que o fenômeno da administrativização do direito penal implica indevida violação da liberdade individual.
\end{abstract}

Palavras-Chave: Estado. Lesividade. Bem jurídico. Liberdade. Norma Penal.

\section{INTRODUÇÃO}

A Revolução Francesa, fato histórico notório de 1789, modificou as relações interpessoais e, sobretudo, a relação entre Estado e sociedade. O paradigma do Estado absolutista, que exercia poderes ilimitados e sem responsabilidade, dava lugar à República, governada pelos princípios da liberdade, igualdade e fraternidade.

\footnotetext{
${ }^{41}$ Mestrando em Direito Penal pela Pontifícia Universidade Católica de São Paulo.
} 
O presente estudo busca, tomando como tema o primeiro elemento da Revolução Francesa, analisar a liberdade como direito fundamental do cidadão e paradigma de limitação do Poder Estatal. De forma ainda mais precisa, será analisada a liberdade como limitação do jus puniendi.

Haverá enfoque em ramo específico do direito penal para que seja possível identificar e adotar um possível critério objetivo que seja capaz de, diante de determinadas normas legais, determinar se o Poder Estatal violou indevidamente a liberdade do cidadão.

O objetivo final do presente estudo pode ser determinado como a busca de um critério jurídico objetivo e eficaz para, diante da legislação que cria os tipos penais, estabelecer a diferenciação entre o uso legítimo e ilegítimo do jus puniendi.

O conceito de bem jurídico protegido pelo direito penal será objeto de análise detida, na medida em que pode fornecer o critério que constitui o objeto do presente estudo.

O estudo do tema é relevante, na medida em que, diante do reconhecimento da existência de uma sociedade de riscos, o direito penal passou a ser utilizado como prima ratio na regulação de comportamentos, gerando uma expansão do direito penal muito além daquela vislumbrada nos primórdios do Estado Liberal.

Para desenvolvimento do objetivo proposto será analisado o processo de expansão do direito penal, sobretudo a administrativização do direito penal. Será preciso analisar se esse específico fenômeno de expansão do direito penal implica ofensa à liberdade do cidadão e, se afirmativo, se haveria algum campo de atuação legítima. Qual seria o critério a ser utilizado para diferenciar a expansão legitima da ilegítima?

O método utilizado será o lógico-dedutivo, com fundamento em revisão bibliográfica dos principais doutrinadores nacionais e estrangeiros que se debruçaram sobre o tema, sem prejuízo da análise de precedentes judiciais quando relevantes para confirmar as conclusões obtidas.

Por fim, o estudo pretende jogar luz sobre a relação entre poder punitivo do Estado e a liberdade individual do cidadão. O objetivo é, diante das discussões dogmáticas sobre o tema, isolar e aplicar um critério objetivo para regular a relação entre direito penal e liberdade.

Ao final do trabalho será possível concluir que o critério objetivo para determinar a legitimidade do jus puniendi é o bem jurídico nos termos delineados por Helena Lobo da Costa. Isto é, bem jurídico definido como valor essencial ao ser humano em determinada realidade, com previsão constitucional de proteção desses interesses. 
A necessidade de que o tipo penal tenha sempre um bem jurídico protegido identificável e delimitado nos termos acima expostos garante que o Poder Estatal não invada a liberdade do indivíduo. Nos países de common law o instituto do bem jurídico seria substituído pelo harm principle.

\section{A DIALÉTICA SOCIAL: ESTADO E LIBERDADE}

A primeira parte do presente artigo busca, mesmo que de forma sumária, adentrar às relações entre Estado e sociedade. Diante do fato de que o Estado Moderno possui o monopólio da força frente ao cidadão, é preciso determinar os limites que moldam as características do poder estatal. Em outras palavras, como realizar o limite do jus puniendi para que seja possível a harmonização do instituto com a liberdade.

Qual o papel da liberdade na relação com os Poderes do Estado é o ponto fulcral desse primeiro trecho.

\subsection{O Estado}

O termo Estado permite diversas definições, conforme o enfoque de análise. As ciências sociais analisam o Estado como personagem político, a Economia toma o Estado como ente externo ao livre mercado com influência sobre as decisões dos particulares, por exemplo.

Para os fins a que se propõe o presente artigo, é importante definir o Estado conforme as ciências jurídicas e, sobretudo, ressaltar qual sua finalidade. A dificuldade em estabelecer um conceito de Estado capaz de abarcar suas principais características é conhecida há muito tempo. Frédéric Bastiat (2010, p. 84) afirma:

Eu gostaria que se instituísse um prêmio, não de 500 francos, mas de um milhão, com guirlandas, medalhas e fitas, em favor de quem conseguisse dar uma boa, simples e inteligente definição para a palavra: ESTADO. Que grande serviço essa pessoa estaria prestando à sociedade! O estado! O que é? Onde ele está? O que fez? O que deveria fazer?

Trata-se de pessoa jurídica de direito público, dotada de soberania. Ou seja, é um ente abstrato criado pelo homem para organizar a vida em sociedade. Para tanto, o Estado passa a 
monopolizar diversas prerrogativas e direitos que antes pertenciam ao homem livre. Os elementos do Estado são: território, povo, soberania e finalidade (bem comum).

Dalmo de Abreu Dallari (1995, p. 60) explicita os elementos do conceito de Estado Moderno:

A maioria dos autores indica três elementos, embora divirjam quanto a eles. De maneira geral, costuma-se mencionar a existência de dois elementos materiais, o território e o povo, havendo grande variedade de opiniões sobre o terceiro elemento, que muitos denominam formal. O mais comum é a identificação desse último elemento com o poder, ou alguma de suas expressões, como autoridade, governo ou soberania. Para DEL VECCHIO, além do povo e do território, o que existe é o vínculo jurídico, que seria, na realidade, um sistema de vínculos, pelo qual uma multidão de pessoas encontra a unidade na forma do direito.

$[\ldots]$

Em face dessa variedade de posições, sem descer aos pormenores de cada teoria, vamos proceder à análise de quatro notas características - a soberania, o território, o povo e a finalidade-, cuja síntese nos conduzirá a um conceito de Estado que nos parece realista, porque considera todas as peculiaridades verificáveis no plano da realidade social.

\section{Celso Ribeiro Bastos (1999, p. 5), ao tratar da formação do Estado Moderno, afirma:}

O Estado - entendido, portanto, como uma forma específica da sociedade política - é o resultado de uma longa evolução na maneira de organização do poder. Ele surge como as transformações por que passa a sociedade política por volta do Século XVI. Nessa altura, uma série de fatores, que vinham amadurecendo ao longo dos últimos séculos do período medieval, torna possível - e mesmo necessária - a concentração do poder numa única pessoa. É esta característica a principal nota formadora do Estado Moderno. O poder torna-se mais abrangente. Atividades que outrora comportavam um exercício difuso pela sociedade são concentradas nas mãos do poder monárquico, que assim passa a ser aquele que resolve em última instância os problemas atinentes aos rumos e aos fins a serem impressos no próprio Estado.

Rousseau (1999, p. 57) sintetiza com precisão a finalidade de criação do Estado:

Quero indagar se pode existir, na ordem civil, alguma regra de administração legítima e segura, tomando os homens como são e as leis como podem ser.

$[\ldots]$

O que o homem perde pelo contrato social é a liberdade natural e um direito ilimitado a tudo quanto aventura pode alcançar. O que com ele ganha é a liberdade civil e a propriedade de tudo que possui. [...] a liberdade natural, [...] só conhece limites nas forças do indivíduo, e a liberdade civil, [...] se limita pela vontade geral.

Murray Rothbard (2012, p. 8) chama a atenção para a concentração de poderes: “o estado é a organização social que visa a manter o monopólio do uso da força e da violência em uma determinada área territorial". 
O Estado é, portanto, um ente abstrato que, por ser dotado de soberania, monopoliza importantes poderes, como o uso da força. Concentra referidos poderes para organização da sociedade e busca do bem comum.

A experiência Francesa até 1789 revelou que os males causados pelas Monarquias Absolutistas só foram possíveis na medida em que o Estado não foi devidamente contido em seus poderes. O poder praticamente ilimitado colocou o homem como instrumento do Estado e não como destinatário de benesses. A sociedade foi dominada pela concentração de Poderes.

Hannah Arendt (1998, p. 949), ao tratar da política após a Segunda Grande Guerra, afirma:

A participação dos cidadãos no governo, qualquer que seja a forma, só é tida como necessária para a liberdade porque o Estado, que necessariamente precisa dispor de meios de força, precisa ser controlado pelos governados no exercício dessa força. Acrescente-se a informação de que, com o estabelecimento de uma esfera por mais que limitada do agir político, surge um poder do qual a liberdade só pode ser protegida se seu exercício for fiscalizado o tempo todo.

(...)

É indiscutível que a restrição e controle ocorrem em nome da liberdade, tanto da sociedade como do indivíduo; trata-se de estabelecer limites, os mais amplos possíveis e necessários, para o espaço estatal do governar, a fim de possibilitar a liberdade fora de seu espaço.

É possível concluir que existe a necessidade de controle e vigilância do Estado, sobretudo diante do monopólio do uso da força. A notória história das Monarquias Absolutistas revela que o poder demanda limites para que a busca do bem comum não seja convertida em tirania.

\subsection{Da liberdade}

A liberdade é fundamento da Constituição dos Estados Unidos da América, cujos benefícios dela decorrentes devem ser garantidos para as futuras gerações, conforme sua declaração $\operatorname{preambular}^{42}$ :

Nós, o Povo dos Estados Unidos, para formar uma União mais perfeita, estabelecemos a Justiça, asseguramos a Tranquilidade doméstica, providenciamos a defesa comum, promovemos o Bem-Estar geral e asseguramos as Bênçãos da Liberdade a nós mesmos e à nossa Posteridade, por ordem e estabelecer esta Constituição para os Estados Unidos da América. (tradução nossa) ${ }^{43}$.

42 ESTADOS UNIDOS DA AMÉRICA. Constituição. Disponível em: https://constitutioncenter.org/media/files/constitution.pdf Acesso em: 15/08/2019.

${ }^{43}$ We the People of the United States, in Order to form a more perfect Union, establish Justice, insure domestic Tranquility, provide for the common defence, promote the general Welfare, and secure the Blessings of Liberty to ourselves and our Posterity, do ordain and establish this Constitution for the United States of America. 
O conceito de liberdade pode ser extraído dos ensinamentos de John Locke (1994, p. 98), ao definir os direitos inerentes ao ser humano:

Sempre que ele tira um objeto do estado em que a natureza o colocou e deixou, mistura nisso o seu trabalho e a isso acrescenta algo que lhe pertence, por isso o tornando sua propriedade. Ao remover este objeto do estado comum em que a natureza o colocou, através do seu trabalho adiciona-lhe algo que exclui o direito comum dos outros homens. Sendo este trabalho uma propriedade inquestionável do trabalhador, nenhum homem, exceto ele, pode ter o direito ao que o trabalho lhe acrescentou, pelo menos quando o que resta é suficiente aos outros, em quantidade e qualidade.

O ensinamento de Locke deu fundamento à liberdade política, entendida como limites horizontais, mas, sobretudo, verticais (limites em relação ao Poder Estatal). Locke busca criar um critério objetivo para determinar a esfera do privado e criar um núcleo duro onde o Estado não poderia penetrar.

Portanto, a liberdade para Locke era a propriedade do fruto do trabalho humano, que não poderia ser invadida por meio de outro ser humano e muito menos pelo Estado. Ao determinar esse conceito de liberdade, Locke criou verdadeira limitação ao Poder Estatal.

Seu ensinamento foi tão profundo que ecoou pelos séculos seguintes. Há pensadores contemporâneos que respaldam a visão de Locke diante da sociedade moderna. David Friedman (1989, p. 6), por exemplo, ao tratar da liberdade individual, afirma:

O conceito de propriedade é fundamental para nossa sociedade, provavelmente para toda sociedade minimamente viável. Operacionalmente, é compreensível por qualquer criança com idade superior a 3 (três) anos. Intelectualmente, não é compreendida por quase ninguém. Considere a afirmação 'direito de propriedade contra direitos humanos'. A força retórica dessa afirmação decorre da premissa que direitos de propriedade são direitos sobre propriedades e direitos humanos são direitos inerentes aos seres humanos; humanos são mais importantes que propriedades (cadeiras, mesas e afins), dessa forma, os direitos humanos prevalecem sobre o direito de propriedade. Mas, direitos de propriedade não são direitos sobre propriedades, são direitos humanos atinentes à propriedade. É um tipo particular de direitos humanos (tradução nossa) ${ }^{44}$.

Friedrich Hayek (1960, p. 140) afirma a necessidade de preservação da propriedade para manutenção da liberdade do indivíduo:

\footnotetext{
44 The concept of property is fundamental to our society, probably to every minimally viable society. Operationally, it is understandable to any child over the age of 3 (three) years. Intellectually, it is not understood by almost anyone. Consider the statement 'property rights against human rights'. The rhetorical force of this statement stems from the premise that property rights are rights over property and human rights are rights inherent in human beings; Human rights are more important than property (chairs, tables and the like), so human rights take precedence over property rights. But property rights are not property rights, they are human rights pertaining to property. It's a particular kind of human rights.
} 
O reconhecimento da propriedade privada é uma condição essencial para a preservação de coerção, embora não o único. Nós, raramente, estamos em condições de levar a cabo um plano coerente de ação a menos que tenhamos certeza do nosso controle exclusivo de alguns objetos materiais; e onde nós não os controlamos, é necessário que nós saibamos quem o faz se formos colaborar com ele. O reconhecimento da propriedade é claramente o primeiro passo na delimitação da esfera privada, que nos protege contra a coerção. [...] Nossa geração tem esquecido que o sistema de propriedade privada é a garantia mais importante de liberdade, não só para aqueles que possuem bens, mas também, para aqueles que não possuem (tradução nossa) ${ }^{45}$.

O pensamento liberal, inaugurado por Locke, tem como núcleo o conceito de propriedade privada para garantir uma limitação ao Poder Estatal.

É preciso reconhecer que as mudanças sociais, especialmente a revolução tecnológica, criaram novos pontos de conflitos entre Estado e cidadão. O critério do respeito à propriedade privada precisava ser ampliado, sobretudo porque o Estado liberou-se das amarras do chamado Estado Mínimo e passou a ter protagonismo em diversas áreas da vida. Há necessidade, portanto, de um novo paradigma para a liberdade.

É preciso, portanto, determinar um conceito de liberdade condizente com os desafios contemporâneos da sociedade.

A proposta que formulamos não envolve negar as premissas fixadas por Locke, mas sua ampliação. Liberdade deve ser conceituada como o livre exercício dos direitos naturais. Os direitos naturais, por sua vez, devem ser definidos nos mesmos moldes defendidos por John Finis (2011, p. 198): “quase tudo nesse livro é sobre direitos humanos ('direitos humanos' sendo uma definição contemporânea de 'direitos naturais': Eu uso os termos como sinônimos) (tradução nossa ${ }^{46}$.

Direitos humanos, portanto, são os direitos naturais inalienáveis. Liberdade é o livre exercício dos direitos naturais, sem obstáculos causados por terceiros ou pelo Estado.

Note-se que não existem direitos absolutos. Logo, pode ocorrer a necessidade de redução proporcional dos direitos humanos, sem que essa redução implique ofensa à liberdade. Trata-se da aplicação da teoria estabelecida por Robert Alexy (2015, p. 94) para determinar a solução jurídica

\footnotetext{
${ }^{45}$ Recognition of private property is an essential condition for preserving coercion, although not the only one. We are rarely in a position to pursue a coherent plan of action unless we are sure of our sole control of some material objects; and where we don't control them, we need to know who does if we are going to collaborate with them. Recognition of property is clearly the first step in delimiting the private sphere, which protects us against coercion.[...] Our generation has forgotten that the private property system is the most important guarantee of freedom, not only for those who own property, but also for those who do not.

46 “almost everything in this book is about human rights ('human rights' being a contemporary definition of 'natural rights': I use the terms synonymously).
} 
em casos de conflitos de princípios. Tomando como fundamento o princípio da proporcionalidade, há redução dos princípios em conflito de forma a harmonizar a interpretação do direito.

Virgílio Afonso da Silva (2014, p. 197) afirma que "restrições a direitos fundamentais que passam no teste da proporcionalidade não afetam o conteúdo essencial dos direitos restringidos."

Friedrich Muller (1969, p. 41) destaca que:

Nenhum direito fundamental é garantido de forma ilimitada. [...] enquanto direitos, eles são fundamentados pela Constituição. Por isso, é necessário, como perspectiva irrenunciável a qualquer teoria constitucional ou, se assim se preferir, como elemento nãoescrito de todos os programas normativos dos direitos fundamentais, sustentar o ponto de vista sistemático-material de seu pertencimento à ordem jurídica (constitucional), do qual decorre a impossibilidade de sua ilimitabilidade (tradução nossa) ${ }^{47}$.

Fixadas as premissas sobre a liberdade, é possível prosseguir no estudo do tema.

\subsection{A Harmonização entre Estado e Liberdade}

A natureza humana impede a convivência em sociedade sem a organização por um ente abstrato que convencionamos chamar de Estado. Marilena Chauí (1995, p. 72) afirma:

Como os humanos realmente são? São seres naturalmente passionais, buscando seu interesse próprio, mesmo com prejuízo para os outros. São naturalmente ambiciosos, invejosos, imprudentes, medrosos, impiedosos; mas também amorosos, compassivos, generosos. Para escrever sobre a política é preciso, portanto, aceitar e compreender os seres humanos tais como são e indagar como e por que decidem instituir o Estado e a vida social.

A figura do Estado é, diante da natureza humana, de fundamental importância para viabilidade da vida em sociedade. A liberdade, primeiro objetivo da Revolução Francesa, deve ser tida não só como um direito humano fundamental, mas sim como uma força contrária ao abuso do poder e à tirania. Liberdade constitui verdadeiro limite objetivo à atuação estatal.

Estado e liberdade são conceitos antagônicos. Onde há atuação estatal não há liberdade. É bem verdade que o ser humano, em sua coletividade, abdica de parte de sua liberdade em prol do Estado que, ao menos em teoria, deveria implantar políticas em prol do bem comum.

\footnotetext{
${ }^{47}$ Kein Grundrecht ist ohne Einschränkung garantiert. [...] als Rechte gründen sie sich auf die Verfassung. Aus diesem Grund ist es als unverzichtbare Perspektive jeder Verfassungstheorie oder, falls bevorzugt, als ungeschriebenes Element aller normativen Grundrechtsprogramme erforderlich, die systematisch-materielle Sichtweise ihrer Zugehörigkeit zur (verfassungs) rechtlichen Ordnung aufrechtzuerhalten), woraus sich die Unmöglichkeit seiner Unbegrenztheit ergibt.
} 
O antagonismo entre poder estatal e liberdade é inerente à formação do Estado e representa a semente de grandes modificações na sociedade, como a Declaração de Independência das Treze Colônias Americanas e da Revolução Francesa.

É verdade que alguns autores identificam o objetivo do Estado com a busca da liberdade. Spinoza (2008, p. 241) afirma:

O fim do Estado, [...] não é fazer os homens passar de seres racionais a bestas ou autômatos: é fazer com que sua mente e o seu corpo exerçam em segurança as respectivas funções, que eles possam exercer em segurança as respectivas funções, que eles possam usar livremente a razão e não se digladiem por ódio, cólera ou insídia, nem se manifestem intolerantes uns para com os outros. O verdadeiro fim do Estado é, portanto, a liberdade.

Não é possível concordar com Spinoza, na medida em que a assunção de poderes pelo Estado implica, logicamente, a restrição de liberdade. Basta pensar na instituição de tributos. A história do direito tributário é marcada pela tensão entre Estado arrecadador e cidadão detentor de patrimônio. Imposto territorial, imposto de renda, contribuições, etc. Há diversos mecanismos que, por meio da força, permitem que o Estado invada o patrimônio do cidadão. A sociedade busca evitar a tributação por meio de planejamentos tributários, realocação de recursos em paraísos fiscais, etc. Conflito entre liberdade individual e estado que se repete em diversos setores.

A declaração de independência das Treze Colônias Americanas evidencia esse confronto entre Estado e liberdade ${ }^{48}$ :

Todos os homens são criados iguais, são dotados pelo seu Criador de certos direitos inalienáveis, que entre estes estão a Vida, a Liberdade e a busca da Felicidade. Que para assegurar esses direitos, os Governos são instituídos entre os Homens, obtendo seus justos poderes do consentimento dos governados, - que sempre que qualquer forma de governo se torne destrutiva desses fins, é o direito do povo de alterá-lo ou aboli-lo, e instituir um novo governo, lançando suas bases em tais princípios e organizando seus poderes em tais forma, como para eles deve parecer mais provável para efetuar a sua segurança e felicidade (tradução nossa) ${ }^{49}$.

É preciso, por meio do respeito à liberdade, instituir limites ao poder estatal em âmbito

${ }^{48}$ ESTADOS UNIDOS DA AMÉRICA. Declaration of Independence, de 04 de julho de 1776. Disponível em: https://www.constitution.org/us_doi.pdf. Acesso em: 21 março. 2017.

${ }^{49}$ All men are created equal, that they are endowed by their Creator with certain unalienable Rights, that among these are Life, Liberty and the pursuit of Happiness. - That to secure these rights, Governments are instituted among Men, deriving their just powers from the consent of the governed, - That whenever any Form of Government becomes destructive of these ends, it is the Right of the People to alter or to abolish it, and to institute new Government, laying its foundation on such principles and organizing its powers in such form, as to them shall seem most likely to effect their Safety and Happiness. 
interno e internacional. O dogma do Poder Estatal deve ceder lugar à ideia de gestão de interesses coletivos por meio de gestores, cujo desempenho deve sempre estar sujeito ao escrutínio coletivo.

Há necessidade de limitar o poder estatal em face do cidadão, tomando a liberdade individual como ponto de contato. Liberdade essa que, como acima já definida, deve ser entendida como o livre exercício dos direitos naturais. Os direitos naturais, por sua vez, devem ser definidos como os direitos humanos fundamentais.

É preciso que as relações entre Estado e cidadão no âmbito interno sofram o mesmo mecanismo de limitação que o dogma da soberania sofreu nas relações internacionais. Flávia Piovesan (2012, p. 42) explicita:

Fortalece-se a idéia de que a proteção dos direitos humanos não deve reduzir-se ao domínio reservado do Estado, porque revela tema de legítimo interesse internacional. (...) Prenuncia-se, desse modo, o fim da era em que a forma pela qual o Estado tratava seus nacionais era concebida como um problema de jurisdição doméstica, decorrência de sua soberania.

Fixada a premissa sobre o ponto de contato entre Estado e liberdade, é possível prosseguir na análise a que o presente estudo se propõe.

\section{A EXPANSÃO DO DIREITO PENAL}

O direito penal decorrente da criação do Estado Liberal foi concebido como um ramo subsidiário do direito. Somente quando outros ramos do direito não fossem capazes de tutelar determinado bem jurídico é que haveria a legitimidade da intervenção do direito penal.

Trata-se, na verdade, da adoção do princípio da proporcionalidade na aplicação do Direito Penal. Afinal, não haveria razoabilidade ou proporcionalidade em proteger determinado bem jurídico com a pena de prisão, quando uma simples multa seria suficiente. Nessas circunstâncias, a pena corporal seria injustificável.

Claus Roxin (1997, p. 65) explica:

A lei criminal é apenas a última de todas as medidas de proteção a serem consideradas, isto é, só pode ser intervir quando outros meios de solução social do problema falharem como ação civil, polícia ou regulamentos legais. técnicas, sanções não criminais, etc. Por esta razão, a punição é a última razão da política social e sua missão é definida como proteção subsidiária de ativos legais. (...) Esta limitação do direito penal decorre do princípio da proporcionalidade, que, por sua vez, pode derivar do princípio do Estado de 
direito de nossa Constituição: como o direito penal torna a interferência mais severa do Estado na liberdade do cidadão, somente eu posso fazê-lo intervir quando outros meios menos difíceis não prometem ser bem sucedido o suficiente (tradução nossa) ${ }^{50}$.

Direito penal, portanto, é norma de aplicação subsidiária. Jamais deve ser utilizada como prima ratio para proteção de bens jurídicos. Esse panorama subsidiário do direito penal sofreu mudanças profundas em um passado recente. Apesar de ter afetado o direito continental, essas mudanças tiveram início em um país de common law.

Os Estados Unidos da América, preocupados com a crescente violência de massa (furtos, roubos, homicídios, etc.) do final dos anos de 1970 e durante toda a década de 1980, buscaram mecanismos para redução da criminalidade. Dentre as várias propostas apresentadas, sagrou-se vitorioso o movimento de lei e ordem.

O movimento de lei e ordem consiste, segundo Vinícius Fernandes Cherem Curi e Mauro Henrique Tavares Duarte (2015, p. 38):

O aludido movimento ideológico propõe o Direito Penal Máximo, ou seja, sugere um alargamento da incidência do Direito Penal, fazendo com que penas mais severas sejam aplicadas, na mesma perspectiva de que as penas já existentes sejam agravadas. Tal proposta faria com que a população acreditasse que o Direito Penal é a solução para acabar com a criminalidade, ou senão, reduzi-la.

Em decorrência dos referidos movimentos, houve uma ampliação da incidência do Direito Penal como forma de controle social.

Esse movimento levou a teste o limite entre Estado e liberdade individual, na medida em que a aplicação de penas severas para crimes menores sob a alegação de incentivo à prevenção geral desafia o princípio da culpabilidade e, sobretudo, a proporcionalidade.

Nesse contexto, surgiu o que Ulrich Beck (2010, p. 24) passou a chamar de sociedade de riscos:

O novo paradigma da sociedade de risco se apoia fundamentalmente na solução de um problema similar e no entanto inteiramente distinto. Como é possível que as ameaças e riscos sistematicamente coproduzidos no processo tardio de modernização sejam evitados,

\footnotetext{
${ }^{50} \mathrm{El}$ derecho penal sólo es incluso la ultima de entre todas las medidas protectoras que hay que considerar, es decir que sólo se le pued hacer intervenir cuando fallen otros médios de solución social del problema - como la acción civil, las regulaciones de polícia o jurídico-técnicas, las sanciones no penales, etc. Por ello se denomina a la pena como la ultima ratio de la política social y se define su misión como protección subsidiaria de bienes jurídicos. (...) Esta limitación del Derecho penal se desprende del princípio de proporcionalidad, que a su vez se puede derivar del princípio del Estado de Derecho de nuestra Constituición: Como el Derecho penal possibilita las más duras de todas las intromisiones estatales em la libertad del ciudadano, sólo se le pued hacer intervenir cuando otros medios menos duros no prometan tener un éxito suficiente.
} 
minimizados, dramatizados, canalizados e, quando vindos à luz sob a forma de "efeitos colaterais latentes", isolados e redistribuídos de modo tal que não comprometam o processo de modernização e nem as fronteiras (ecológica, medicinal, psicológica ou socialmente) do que é aceitável?

Influenciados pela experiência do movimento Lei e Ordem no combate à criminalidade de massas (uso de drogas, furtos, roubos), os Estados passaram a ver no direito penal a solução não só para a eventual redução de crimes, mas também como forma de impor novos comportamentos. Em outras palavras, a ameaça da lei penal seria um método eficaz para a proteção de bens difusos, cuja demanda social se tornava cada vez mais crescente.

Silva Sanchez (2001, p. 20) afirma:

A criação de novos «bens jurídico-criminais», a ampliação dos espaços de riscos juridicamente criminalmente relevantes, a flexibilização das regras de imputação e a relativização dos princípios políticos criminais de garantia seriam apenas aspectos desta tendência geral, à qual se pode fazer referência com o termo "expansão" (tradução nossa $)^{51}$.

A questão que se pode colocar é, essa expansão do direito penal é legítima? Quando se admite a expansão em face do surgimento de novos bens que demandam extrema proteção sob pena de causar graves danos (meio ambiente) a intervenção penal pode ser considerada legítima.

Contudo, quando essa intervenção penal se faz como uma solução para substituir outras soluções eficazes que deixaram de ser adotadas, a expansão não encontra respaldo. Mais uma vez Silva Sanchez (2001, p. 26) explicita:

O que é interessante destacar neste momento é apenas que há certamente um espaço de "expansão razoável" do direito penal. Embora com a mesma convicção próxima à segurança, deve-se afirmar que também há importantes manifestações de "expansão não razoável". Para propósitos puramente indicativos: o ingresso maciço de capital de atividades criminosas (singularmente, de tráfico de drogas) em um determinado setor da economia provoca uma profunda desestabilização do mesmo com repercussões prejudiciais importantes. Portanto, é provavelmente razoável que a pessoa ou pessoas responsáveis por uma injeção maciça de dinheiro negro em um setor particular da economia seja penalizada por cometer um crime contra a ordem econômica. No entanto, isso não significa, sem mais, a sanção penal de qualquer conduta de usar pequenas (ou médias) quantias de dinheiro negro na aquisição de bens ou na retribuição de serviços. A definição do crime de lavagem de dinheiro é, em suma, uma manifestação de razoável expansão do direito penal (em sua essência, de escopo muito limitado) e de expansão irracional do mesmo (em outros comportamentos, dos quais não se pode afirmar de

\footnotetext{
${ }^{51}$ Creación de nuevos «bienes jurídico-penales», ampliación de los espacios de riesgos jurídico-penalmente relevantes, flexibilización de las reglas de imputación y relativización de los principios político criminales de garantía no serían sino aspectos de esta tendência general, a la que cabe referirse con el término «expansión».
} 
maneira alguma, que um por um, eles prejudicam a ordem econômica de maneira criminalmente relevante (tradução nossa) ${ }^{52}$.

Feitas essas ponderações, passamos a analisar uma expansão irrazoável do direito penal, que afeta a liberdade do indivíduo de forma ilegítima.

\subsection{Administrativização do Direito penal.}

Processo específico do movimento de expansão do direito penal, a administrativização do direito penal é assim definida por Silva Sanchez (2001, p. 130):

Pode-se afirmar que é uma característica do Direito Penal das sociedades pós-industriais o assumir, em ampla medida, a forma de raciocínio tradicionalmente própria do administrativo. É isso que se quer indicar quando se alude ao processo de administrativização em que, em nosso juízo, está imerso o direito penal. Isto poderia ser levado ainda mais longe: afirmando não só que o direito penal assume o modo de raciocínio próprio do direito administrativo sancionatório, mas também que se converte, inclusive, em um direito de gestão ordinária de problemas sociais (tradução nossa $)^{53}$.

Bernardo Feijoo Sanchez (2011, p. 25), ao tratar do instituto aqui em análise, afirma:

O Direito Penal cria novos tipos penais com que intervém em novos âmbitos dos quais tradicionalmente se vinha ocupando o direito administrativo ou dos quais somente se havia ocupado mediante os delitos de lesão tradicionais. É paradigmática a criação de tipos penais que vão protegendo funções estatais e a criação de delitos de perigo abstrato.

Conforme definição acima, a administrativização implica tornar crime procedimentos que violam, somente, interesses da administração. Em outras palavras, a administrativização do direito penal torna crime violações de normas que não afetam bem jurídicos passíveis de tutela penal.

\footnotetext{
${ }^{52}$ Lo que interesa poner de relieve en este momento es tan sólo que seguramente existe un espacio de «expansión razonable» del Derecho penal. Aunque con la misma convicción próxima a la seguridad deba afirmarse que también se dan importantes manifestaciones de la «expansión irrazonable». A título puramente orientativo: la entrada masiva de capitales procedentes de actividades delictivas (singularmente, del narcotráfico) en un determinado sector de la economía provoca una profunda desestabilización del mismo con importantes repercusiones lesivas. Es, pues, probablemente razonable que el o los responsables de una inyección masiva de dinero negro en un determinado sector de la economía sean sancionados penalmente por la comisión de un delito contra el orden económico. Ahora bien, ello no hace, sin más, razonable la sanción penal de cualquier conducta de utilización de pequeñas (o medianas) cantidades de dinero negro em la adquisición de bienes o la retribución de servicios. La tipificación del delito de blanqueo de capitales es, en fin, una manifestación de expansión razonable del Derecho penal (en su núcleo, de muy limitado alcance) y de expansión irrazonable del mismo (en el resto de conductas, de las que no puede afirmarse en absoluto que, una por una, lesionen el orden económico de modo penalmente relevante)

53. Se puede decir que es una característica del Derecho Penal de las sociedades posindustriales asumir, en gran medida, la forma de razonamiento tradicionalmente propio de la administración. Esto es lo que queremos indicar cuando nos referimos al proceso de administración en el que, a nuestro juicio, el derecho penal está inmerso. Esto podría llevarse aún más lejos al afirmar que el derecho penal no solo asume el modo de razonamiento adecuado para sancionar el derecho administrativo, sino que también se convierte en un derecho de gestión ordinaria de los problemas sociales.
} 
Afinal, a finalidade do direito penal não é servir de instrumento para o cumprimento de ordens administrativas.

Bernardo Feijoo Sanchez (2011, p. 40), mais uma vez, esclarece que:

As normas penais que, por sua redação, impedem que materialmente se possa encontrar a retribuição a um injusto concreto merecedor da pena, enquanto organização defeituosa, carecem de legitimidade. Por exemplo, a condução sob influência de bebidas alcoólicas (art. 379, CP) é um tipo legítimo enquanto - como geralmente fazem a doutrina e a jurisprudência - não se castiga somente o superar dos limites estabelecidos pela lei de segurança rodoviária, mas, para além disso, que essas cifras se utilizem como indício de que o condutor carecia de uma capacidade mínima para controlar seu veículo (seu âmbito de organização perigoso).

Não há legitimidade para criação de tipo penal quando a conduta descrita no tipo não revelar violação a nenhum bem jurídico protegido. É preciso destacar que a afirmação acima não implica defender que o Estado não possa determinar comportamentos em busca da convivência pacífica. Ao regular o trânsito de veículos, por exemplo, o Estado pode determinar política de tolerância zero ao álcool e estabelecer sanções para o motorista que violar a norma. Contudo, no que tange ao crime, não basta mera ingestão de álcool. É preciso que a ingestão gere, ao menos, perigo para bem jurídico protegido.

A legislação pátria fornece exemplo ainda mais claro do processo de administrativização do direito. O artigo $1^{\circ}$ da Lei 8.137/90 estabelece o crime de sonegação fiscal. A sonegação fiscal, em sua redação original, não envolvia o mero inadimplemento de tributos, mas um elemento de fraude em face do Estado arrecadador.

Pois bem, se o bem jurídico protegido pela sonegação fiscal fosse a manutenção da regular relação entre Estado e cidadão, vale dizer, o impedimento à utilização de fraude para evitar a arrecadação de tributos, haveria legítima proteção do bem jurídico.

Contudo, o que a análise sistemática revela é que o crime de sonegação fiscal passou a ser, somente, uma forma de ameaça para que o cidadão realize o recolhimento espontâneo do tributo. Vale dizer, a análise global revela que não há bem jurídico protegido, mas somente a finalidade arrecadatória do Estado.

De fato, a promulgação da Lei Federal 10.684/2003 facultando o recolhimento do tributo a qualquer tempo como causa de extinção da punibilidade penal determinou como finalidade única do tipo penal a arrecadação de valores. Já não mais havia o objetivo de preservação contra fraudes nas declarações. 
O direito penal tornou-se mero gestor de interesses tributários que poderiam ser satisfeitos com a imposição de multas e com um sistema de cobrança extrajudicial e judicial eficaz.

Esse é o típico caso de administrativização do direito penal, onde o crime é apenas um reforço de interesses administrativos. Vale dizer, a norma penal é utilizada de forma simbólica para, com ameaça da pena, obrigar o cidadão a realizar o recolhimento do tributo.

O fenômeno da administrativização do direito penal comprova a premissa do presente trabalho. Isto é, o conflito entre poder estatal e liberdade individual na aplicação do direito penal. A administrativização do direito penal é a invasão ilegítima da liberdade do indivíduo.

\section{O BEM JURÍDICO}

A solução para o conflito acima exposto é a prevalência da liberdade em detrimento da ilegítima expansão do direito penal. É importante, contudo, determinar qual o critério objetivo a ser utilizado para diferenciar a norma penal legítima da ilegítima, de forma a manter o equilíbrio entre Poder Estatal e liberdade individual.

O critério proposto é a existência de bem jurídico a ser protegido pela norma penal. Sem a identificação de um bem jurídico protegido, o tipo penal não pode ser tido como legítimo. Juarez Tavares (2018, p.39) afirma:

a partir dessa relação entre proibição e bem jurídico, será possível construir um sistema dogmático capaz de superar seu conteúdo meramente simbólico, caso se passe a exigir que a lesão ou o perigo de lesão desses bens constitua o fundamento essencial da incriminação, o que, então, justificaria a importância dessa análise em face da necessidade de se traçar uma perfeita linha divisória entre as zonas do lícito e do ilícito penal. Esta separação das zonas do lícito e do ilícito é uma condição de garantia da liberdade da pessoa humana e só pode ser satisfeita se formalizada por meio de um processo de comunicação absolutamente claro quanto ao conteúdo e às consequências das proibições ou imposições legais. Somente com o estímulo e a manutenção de um processo correto de comunicação quanto ao que é proibido e ao que é mandado pela norma se poderá assegurar a todos, em um primeiro momento da avaliação jurídica, uma atuação controlada quanto às suas expectativas de conduta e delimitar, ademais, o processo de sua imputação no tipo respectivo.

Declarar a necessidade de que o direito penal, para ser legítimo, deve buscar a proteção de bem jurídico é uma premissa correta, mas que demanda aprofundamento. Afinal, o que seria bem jurídico protegido? Como estabelecer um critério objetivo para determinar o limite entre direito penal legítimo e administrativização do direito penal? 
Pensamos que a solução para a questão foi delineada por Helena Regina Lobo da Costa (2010, p. 5)

O cerne de nosso sistema valorativo é a pessoa humana. O Direito e o Estado existem para servir à pessoa, decorrendo daí ser ela o ponto de partida para a construção do conceito de bem jurídico. Assim, apenas os elementos tidos como essenciais para o desenvolvimento da pessoa numa determinada realidade social podem ser alçados à categoria de bens jurídicos.

(...)

Ao lado disso, tais elementos devem estar previstos constitucionalmente.

O critério adotado por Helena Regina Lobo da Costa envolve dois elementos básicos para determinação do bem jurídico passível de proteção pelo direito penal, isto é, valores essenciais ao ser humano em determinada realidade e a previsão constitucional de proteção desses interesses.

Como bem ressalta Helena Regina Lobo da Costa (2010, p. 6), a Constituição deve ser tida como um limite negativo ao direito penal no momento de eleger bem jurídico protegido:

A Constituição é apenas um limite negativo ao direito penal, ou seja, não há qualquer obrigação de se criminalizarem condutas que lesionam ou ameaçam bens jurídicos, ainda que haja determinação constitucional. Isso porque a proteção de um bem jurídico é pressuposto inarredável do tipo penal, mas de forma suficiente.

Julgamos que o critério acima exposto é correto e suficiente para a determinação do bem jurídico passível de proteção penal, sendo um mecanismo para estabelecer o limite entre liberdade e poder estatal.

O critério apresentado adota como premissa a aplicação do direito continental. Contudo, pensamos que a mesma solução seria aplicada em um país de common law. A única diferença é que o conceito de bem jurídico seria substituído pelo Harm Principle. Nesse sentido, Albin Eser (1966, p. 346):

o dano é um elemento substantivo essencial de todo crime. Pode até ser chamado de ratio essendi do crime, pois é o dano criminal infligido que torna a conduta do perpetrador sancionável. Além disso, uma vez que a evidência de dano é um resultado externo, a exigência de um certo dano proibido é valiosa como um critério para distinguir a conduta criminosa do comportamento meramente imoral (isto é, da ética pura) (tradução nossa) ${ }^{54}$.

\footnotetext{
${ }^{54} \mathrm{Harm}$ is an essential substantive element of every crime. It may even be called the ratio essendi of the crime, for it is the criminal harm inflicted that makes the perpetrator's conduct sanctionable. In addition, since the evidence of harm is an external result, the requirement of a certain proscribed harm is valuable as a criterion in order to distinguish criminal conduct from merely immoral behavior (i.e., from pure ethics).
} 
A premissa aqui defendida não foi inicialmente acolhida, por exemplo, pela Suprema Corte do Canadá que, ao julgar o caso Malmo-Levine ${ }^{55}$, afastou, por maioria, o harm principle como elemento fundamental para configuração do crime (o caso envolvia o pedido de declaração de inconstitucionalidade de norma que impedia o consumo de entorpecentes, por ausência de danos a terceiros).

Contudo, em julgamento posterior, caso Bedford ${ }^{56}$, a Suprema Corte Canadense modificou seu entendimento e reconheceu a aplicação do harm principle. No referido julgamento, a corte declarou a inconstitucionalidade de norma por entender que a conduta tipificada não afetava interesse coletivo passível de tutela penal.

É possível afirmar, portanto, que o bem jurídico nos moldes delineados por Helena Lobo da Costa constitui elemento seguro para verificação da legitimidade da norma penal, constatando a legitimidade do bem jurídico protegido.

\subsection{Os crimes de perigo abstrato}

Os crimes de perigo abstrato têm, como principal característica, a antecipação da tutela penal. É necessária, somente, a prática de conduta descrita pela norma penal, ainda que não exista dano ou perigo concreto.

Assim, ao afirmar que o perigo abstrato isoladamente legitimaria a incidência da norma penal, seria possível concluir que a norma penal não demandaria a proteção de bem jurídico, mas somente a prática de uma conduta.

Entendemos que a afirmação acima não se trata da melhor conclusão, sendo certo que os crimes de perigo abstrato devem obedecer aos mesmos critérios de legitimidade dos crimes de danos e de perigo concreto.

Os crimes de perigo abstrato devem determinar, de forma precisa, qual o bem jurídico protegido. Afinal, não basta declarar qual o bem jurídico protegido; é necessário eleger condutas potencialmente danosas ao bem.

\footnotetext{
${ }^{55}$ CANADA. Supreme Court. R v Malmo-Levine; R v Caine [2003] 3 S.C.R. 571, 2003 SCC 74

${ }^{56}$ CANADA. Supreme Court. Canada (AG) v Bedford 2013 SCC 72, [2013] 3 SCR 110.
} 
Portanto, mesmo nos crimes de perigo abstrato é necessária a vinculação ao bem jurídico protegido nos termos aqui defendidos (valores essenciais ao ser humano e previstos na Constituição). Inexistentes esses elementos, o tipo penal deve ser declarado inconstitucional.

Note-se que essa antecipação da tutela penal promovida pelos crimes de perigo abstrato deve sofrer, além das limitações apontas, uma outra condicionante. Referidos tipos penais somente podem ser tidos como legítimos quando forem fundamentados no princípio da precaução. Isto é, quando a opção legislativa por punir determinada conduta após a ocorrência efetiva do dano seja capaz de gerar consequências nefastas para a sociedade.

Pierpaolo Cruz Bottini (2013, p. 48) afirma:

O termo precaução deriva do latim tardio precautio-onis, que significa cautela antecipada. O princípio da precaução, princípio da prudência ou princípio da cautela, pode ser conceituado como a diretriz para a adoção de medidas de regulamentação de atividades, em casos de ausência de dados ou informações sobre o potencial danoso de sua implementação. É o princípio que lida com situações em que a ciência não pode providenciar uma ampla análise das consequências, deixando um grau de incerteza, no que se refere aos efeitos de determinadas atividades.

Assim, há necessidade de harmonizar o ordenamento para reduzir proporcionalmente o âmbito de incidência do princípio da lesividade (que imporia a aplicação da sanção penal somente após o dano), de forma a permitir que o direito penal tutele os bens (especialmente os difusos) antes da efetiva lesão.

Resta demonstrado, portanto, que a existência de crimes de perigo abstrato não afeta a conclusão aqui obtida sobre a necessidade de identificação de bem jurídico essencial para legitimidade do tipo penal.

\subsection{Teoria funcionalista extrema}

As teorias funcionalistas extremas do direito penal poderiam ser consideradas como um contraponto aos argumentos acima expostos, na medida em que não conceituam o direito penal como a proteção do bem jurídico.

As chamadas teorias funcionalistas extremas têm o direito penal como um instrumento para garantia da efetividade da norma. Vale dizer, a função do direito penal não seria a proteção de bens jurídicos previamente selecionados, mas a utilização da força para garantia do respeito à legislação vigente. 
Função do direito penal seria, portanto, o reforço para que a sociedade cumpra as leis. Isto é, nada mais seria do que a imposição da força diante da constatação da violação das normas jurídicas. Essa seria a função e finalidade do direito penal, não existindo, em tese, campo para limitação decorrente da interpretação referente ao bem jurídico protegido.

Günther Jakobs (2013, p. 584), tido como representante da teoria funcionalista pura ou extremada, afirma:

O conceito de culpabilidade, portanto, deve ser configurado funcionalmente, isto é, como um conceito que produz um resultado de regulação, de acordo com certos princípios de regulação (de acordo com os requisitos do fim da pena), para uma determinada estrutura social. O fim da penalidade é, segundo a concepção aqui desenvolvida, de um tipo geral preventivo; trata-se de manter o reconhecimento geral da norma (não intimidação ou advertência) (tradução nossa) ${ }^{57}$.

A adoção da premissa que a função do direito penal é tão somente prevenir o descumprimento da norma penal para manter a integridade do sistema normativo não pode ser levada ao extremo. De fato, para que a teoria possa ser acolhida em um regime de Estado de Direito, é necessário impor limites ao poder punitivo. Não se concebe como se possa estabelecer os fundamentos de um Estado de Direito, sem a imposição de limites objetivos ao poder estatal.

Gerson Faustino Rosa e Gisele Mendes de Carvalho (2017. p. 51), ao tratarem da teoria funcionalista do direito penal, destacam as consequências da aplicação das teorias funcionalistas no Estado Moderno:

Segundo a visão funcionalista sistêmica, compete ao Direito, como regulador social, delimitar o âmbito das expectativas normativas da conduta. Esse é o alicerce metodológico da teoria funcionalista sistêmica desenvolvida por Günther Jakobs para o Direito Penal. Ressalte-se, por derradeiro, que a função social de uma atividade será definida, então, pela sua utilidade na manutenção, conservação e permanência do todo. Logo, se uma atividade não trouxer qualquer benefício para o bom andamento da sociedade, ela não é funcional, e por isso, prescindível, descartável, desprezível. Há, portanto, verdadeira inversão de valores e ordem de prioridades, uma vez que, em última análise, ter-se-á como consequência a colocação do homo noumenon em segundo plano, e não mais como prioridade da humanidade, que passa a ser a sociedade, o funcionamento adequado do mundo, do todo. Como se tal coisa fosse possível.

Tem-se um esvaziamento completo da dignidade humana, pois o ser humano passa a ser mais uma etapa do funcionamento da coletividade, do Estado, sendo que tudo isso é criação do homem para o homem, e não o contrário. Há uma sobreposição completa, desequilibrada, do Estado social sobre a concepção iluminista de Estado liberal. Por isso,

${ }^{57}$ El concepto de culpabilidade, por tanto, há de configurarse funcionalmente, es decir, como concepto que rinde um fruto de regulación, conforme a determinados principios de regulación (de acuerdo com los requisitos del fin de la pena), para uma sociedade de estrutura determinada. El fin de la pena es, según la concepción aqui desarrollada, de tipo preventivo-general; se trata de mantener el reconocimiento general de la norma (no de intimidación o escarmiento). 
inconcebível, inadmissível e inaceitável a manutenção desta teoria sociológica para explicar o "adequado" funcionamento da humanidade, pois, além do que foi dito, ela não é exatamente dinâmica como a sociedade e as pessoas.

As teorias funcionalistas, portanto, precisam ser delimitadas no âmbito de sua atuação, sob pena de violação às liberdades básicas do cidadão. Portanto, mesmo admitindo a função do direito como a garantia da estabilidade do sistema (garantia da efetividade das normas), há necessidade de estabelecer um critério para limitar o campo de atuação penal.

Assim, para viabilidade das teorias funcionalistas, é preciso coordená-las com a proteção do bem jurídico nos termos aqui expostos. A função de manutenção do sistema e garantia da efetividade do direito encontra limites no conceito de bem jurídico essencial ao ser humano.

Claus Roxin (2006, p. 19), mesmo adotando a teoria funcionalista, ressalta a necessidade de limitação do direito penal por meio do bem jurídico:

objetos legítimos de proteção das normas que subjacem a estas condições, circunstâncias reais dadas ou finalidades necessárias para uma vida segura e livre, que garanta todos os direitos humanos e civis de cada um na sociedade ou para o funcionamento de um sistema estatal que se baseia nestes objetivos.

Verifica-se, portanto, que as teorias funcionalistas extremadas do direito penal não afastam a conclusão obtida nesse estudo. Ao contrário, a interpretação sistemática das referidas teorias, sobretudo no contexto do Estado de Direito, demonstra a efetividade do conceito definido no caso do presente artigo.

\section{CONSIDERAÇÕES FINAIS}

O presente trabalho teve como ponto de partida a tensão entre poder estatal e liberdade individual. Com a nova configuração do Estado moderno após a Revolução Francesa e Declaração de Independência das Treze Colônias Americanas, o poder estatal passou a ser limitado pela liberdade individual. Não havia mais espaço para governos absolutistas, mas somente Estados voltados ao bem comum.

A pesquisa realizada baseou-se em revisão bibliográfica de doutrinadores nacionais e estrangeiros. A pesquisa de jurisprudência, sobretudo as decisões proferidas em outros países, 
ocorreu com a finalidade de comprovar os ensinamentos dogmáticos e foi objeto de menção quando relevante para o deslinde da questão.

A primeira parte do trabalho foi dedicada à dialética social entre Estado e Liberdade. Houve análise, em segmentos distintos, do conceito de Estado e de liberdade, bem como a interação dos dois institutos.

Foi possível concluir que o Estado pode ser conceituado como um ente abstrato criado pelo homem para organização da vida em sociedade. O Estado moderno formado após a Revolução Francesa monopoliza prerrogativas para a busca do bem comum, como o uso da força.

O homem, para formação desse ente abstrato, abdica de parte de sua liberdade em prol do Estado, de forma a conferir meios para viabilizar a vida harmônica no seio da sociedade.

Houve análise do conceito de liberdade que, apesar das diversas acepções, foi determinada como o livre exercício dos direitos naturais, sem obstáculos causados por terceiros ou pelo Estado.

Ao final da primeira parte foi realizada a análise das interações entre poder estatal e liberdade, de forma a delinear como esses dois institutos se relacionam na sociedade atual.

Concluiu-se que há necessidade de limitar o poder estatal em face do cidadão, tomando a liberdade individual como ponto de contato. Liberdade essa que, como acima já definida, deve ser entendida como o livre exercício dos direitos naturais.

Evidenciou-se que não existe nenhum direito absoluto (mesmo os direitos naturais). Contudo, sua redução deve ser feita de forma criteriosa e sempre respeitando o princípio da proporcionalidade.

Na segunda parte do estudo houve a análise do Direito Penal e do Processo de administrativização que, como verificado, trata-se de uma parte específica do processo de expansão indevida do direito penal.

Demonstrou-se que a tensão entre poder estatal e liberdade é muito pronunciada no direito penal, diante da gravidade das sanções impostas.

Não se pode permitir o processo de administrativização, na medida em que a utilização da sanção penal para impedir violações de normas cujo interesse primordial é a manutenção de normas administrativas viola o princípio da proporcionalidade.

Como critério objetivo para determinar o limite entre a legítima instituição do direito penal e o ilegítimo processo de administrativização (isto é, critério para fixar a proporcionalidade), foi eleito o conceito de bem jurídico, nos termos delineados por Helena Lobo da Costa. 
O Bem Jurídico foi definido como o valor essencial ao ser humano em determinada realidade e a previsão constitucional de proteção desses interesses.

A necessidade de que o tipo penal tenha sempre um bem jurídico protegido identificável garante que o poder estatal não invada a liberdade do indivíduo. Em outras palavras, garante a aplicação proporcional do jus puniendi.

As afirmações até aqui expostas parecem confirmadas mesmo em regimes de commom law. Nesses regimes jurídicos, a figura do bem jurídico seria substituída pelo harm principle, de forma a exercer a mesma função, qual seja, impedir o exercício do poder estatal sem limites.

Julgamos que o presente estudo permitiu, tendo como foco o direito penal, determinar critério seguro para preservar a liberdade individual e limitar o poder estatal.

Outrossim, resta fortemente demonstrado que a regularidade formal (lei ordinária) é apenas uma etapa no processo de criação do tipo penal pelo Estado, sendo essencial a regularidade material, vale dizer, a definição precisa de um bem jurídico passível de proteção (interesse humano relevante e respaldado na Constituição).

\section{REFERÊNCIAS}

ALEXY, Robert. Teoria dos Direitos Fundamentais. 2 ed. Tradução de Virgílio Afonso da Silva. São Paulo: Editora Malheiros, 2015.

ARENDT, Hannah. O que é a Política? 1 ed. Versão para eBook. São Paulo: Bertrand Brasil, 1998. Acesso em: 14 agosto 2019.

BASTIAT, Frédéric. Frédéric Bastiat. 2 ed. São Paulo: Instituto Ludwig Von Misses Brasil, 2010.

BASTOS, Celso Ribeiro. Curso de Direito Constitucional. 20 ed. São Paulo: Saraiva, 1999.

BECK, Ulrich. Sociedade de Risco - Rumo a uma outra modernidade. 1 ed. Trad. Sebastião Nascimento. São Paulo: Editora 34, 2010.

BOTTINI, Pierpaolo Cruz. Crimes de perigo abstrato. 3 ed. São Paulo: Revista dos Tribunais, 2013.

CANADA. Supreme Court. Canada (AG) v Bedford 2013 SCC 72, [2013] 3 SCR 110.

CANADA. Supreme Court. R v Malmo-Levine; R v Caine [2003] 3 S.C.R. 571, 2003 SCC 74. 
CARVALHO, Gisele Mendes de; ROSA, Gerson Faustino. Funcionalismo Sistêmico e Direitos Fundamentais na Seara Penal. Revista Pensamento Jurídico - São Paulo - Vol. 11, Nº 2, jul./dez. 2017. P. 40/64

CHAUÍ, Marilena de Souza. Espinosa: uma filosofia da liberdade. 1 ed. São Paulo: Moderna, 1995.

COSTA, Helena Regina Lobo da. Proteção Penal Ambiental: viabilidade - efetividade-tutela por outros ramos do direito. 1 ed. São Paulo: Saraiva, 2010.

CURI, Vinícius Fernandes Cherem; DUARTE, Mauro Henrique Tavares. Os influxos do Movimento Law and Order e The Broken Windows Theory no Brasil. Revista Liberdades, n. 19. São Paulo: IBCCRIM: 2015. P. 35/44.

DALLARI, Dalmo de Abreu. Elementos de Teoria Geral do Estado. 19 ed. São Paulo: Saraiva, 1995.

ESER, Albin. The Principle of "Harm" in the concept of crime: A comparative analysis of the criminally protected legal interests. Duquesne University Law Review, n. 04. Nova York. 1966. p. $345 / 417$.

ESTADOS UNIDOS DA AMÉRICA. Constitution. Disponível em: https://constitutioncenter.org/media/files/constitution.pdf Acesso em: 15/08/2019.

Declaration of Independence, de 04 de julho de 1776. Disponível em: https://www.constitution.org/us_doi.pdf. Acesso em: 21 março. 2017.

FINIS, John. Natural Law \& Natural Rights. 2 ed. London: Oxford University Press, 2011.

FRIEDMAN, David. The Machinery of Freedom - Guide to a Radical Capitalism. 2 ed. La Salle, IL: Open Court, 1989.

HAYEK, Friedrich. The Constitution of Liberty. 1 ed. Chicago: The University of Chicago Press, 1960.

JAKOBS, Günther. Derecho Penal. Parte Geral - Fundamentos y Teoría de la Imputacíon. 2 Ed. Barcelona: Marcial Pons, 2013.

LOCKE, John. Segundo Tratado sobre o Governo Civil - Ensaio sobre a origem, os limites e os fins verdadeiros do governo civil - e outros escritos. 1 ed. Petrópolis: Vozes, 1994.

MULLER, Friedrich. Die Positivitat der Grundrechte. Fragen einer praktischen Grundrechtsdogmatik. 1 ed. Berlin: Duncker \& Humblot, 1969.

PIOVESAN, Flávia. Direitos Humanos e Justiça Internacional. 3 ed. São Paulo: Saraiva, 2012. 
ROTHBARD, Murray. A Anatomia do Estado. 1 ed. São Paulo: Instituto Ludwig Von Misses Brasil, 2012.

ROUSSEAU. Jean Jaques. Do contrato social. 2 ed. Tradução de Lourdes Santos Machado. São Paulo: Nova Cultural, 1999.

ROXIN, Claus. Derecho penal: parte general - tomo I. Fundamentos: las estructuras de la teoria del delito. Trad. Diego-Manuel Luzón Peña et all. 1 ed. Madrid: Civitas, 1997.

. A proteção de bens jurídicos como função do direito penal. 1 ed. Tradução de André Luís Callegari e Nereu José Giacomolli. Porto Alegre: Livraria do Advogado, 2006.

SANCHEZ, Bernardo Feijoo. Sobre a "Administrativização" do Direito Penal na "Sociedade do Risco". Notas sobre a Política Criminal no Início do Século XXI. Revista Liberdades, n. 07. São Paulo: IBCCRIM, 2011. P. 23/62.

SANCHEZ, Jesus Maria Silva. La Expansión Del Derecho Penal - Aspectos de La Política Criminal en las sociedades postindustriales. 2 ed. Madri: Civitas Ediciones, 2001.

SILVA, Virgílio Afonso da. Direitos Fundamentais: conteúdo essencial, restrições e eficácia. 2 ed. São Paulo: Malheiros, 2014.

SPINOZA, Benedictus de. Tratado Teológico-político. 2 ed. Tradução, introdução e notas Diogo Pires Aurélio. São Paulo: Martins Fontes, 2008.

TAVARES, Juarez. Teoria do crime culposo. 5 ed. Florianópolis: Empório do Direito, 2018.

\title{
THE EXPANSION OF CRIMINAL LAW AND FUNDAMENTAL RIGTH TO
}

\section{FREEDOM}

\begin{abstract}
The present paper seeks to study the conflict between state power and individual freedom. Today's society demands the existence of an abstract entity (state) with a monopoly on the use of force, whose function is to regulate coexistence in the pursuit of the common good. This construction conflicts with individual freedom. Whenever the state makes use of force, such as the creation of a criminal type, individual freedom is restricted. There is a need to establish an objective criterion to set the limit of state power, given the individual freedom. The proposal tests and confirmed was that, for the countries of continental law, the use of the protected legal property concept was a way to verify the legitimacy of the norm. Commom law countries would use the same mechanism, but the concept of protected legal property would be replaced by the harm principle. The phenomenon
\end{abstract}


of the administrativization of criminal law has been shown to imply undue violation of individual freedom.

Keywords: State. Harm Principle. Legal Entity. Freedom. Criminal Law. 